\title{
Erratum to: Advances in Wireless Video Capsule Endoscopy
}

\author{
Muzaffer Kanaan $^{1} \cdot$ Hamed Farhadi ${ }^{2}$
}

Published online: 5 May 2017

(C) Springer Science+Business Media New York 2017

\section{Erratum to: Int J Wireless Inf Networks DOI 10.1007/s10776-017-0350-7}

The original version of this editorial was published with an inappropriate title. The correct title is "Advances in Wireless Video Capsule Endoscopy".

This has been corrected in the original version of the article.

The online version of the original article can be found under doi:10.1007/s10776-017-0350-7.

$\triangle$ Muzaffer Kanaan mkanaan@erciyes.edu.tr

Hamed Farhadi

farhadi@seas.harvard.ed

1 Erciyes University, Kayseri, Turkey

2 Harvard University, Cambridge, MA, USA 